\title{
Level of Prior Education as a Predictor of Academic Performance in the Bio Science Papers
}

\author{
Rohini Khareedi ${ }^{1 *}$ and Jyoti Jhagroo ${ }^{2}$ \\ ${ }^{1}$ Oral Health Department, New Zealand \\ ${ }^{2}$ Lecturer, New Zealand
}

ISSN: 2637-7764

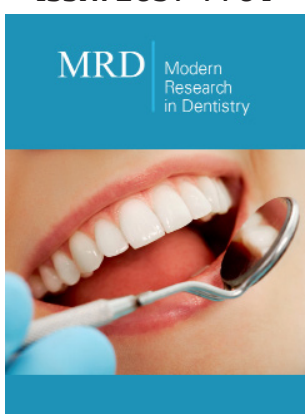

*Corresponding author: Rohini Khareedi, Oral Health Department, New Zealand

Submission: 1-ien March 29, 2019

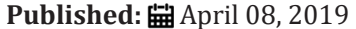

Volume 3 - Issue 5

How to cite this article: Rohini $\mathrm{K}$, Jyoti J. Level of Prior Education as a Predictor of Academic Performance in the Bio Science Papers. Mod Res Dent. 3(5). MRD.000574.2019.

DOI: 10.31031/MRD.2019.03.000574

Copyright@ Rohini Khareedi, This article is distributed under the terms of the Creative Commons Attribution 4.0 International License, which permits unrestricted use and redistribution provided that the original author and source are credited.

\begin{abstract}
Background: The cohort of students enrolled in the bio science papers at the Bachelor of Health Science (Oral Health) programme reflects a structural diversity in that it includes students of differing levels of prior education. The purpose of this retrospective quantitative study was to determine if the level of prior education, is a predictor of academic performance in the bio science papers.
\end{abstract}

Methods: The sample for this study was a purposive sample of all oral health students who had enrolled in the first- and second-year bio science papers at the Auckland University of Technology from 2011 to 2014. The desensitized empirical data of 116 students from the University's database was subject to independent sample $t$ tests and multivariable regression analysis.

Results: The independent sample $t$ tests with $p$ values of $>0.05$ indicated that there was no difference in the bio science performance of students with and without prior university qualifications. The multiple variable regression analysis with $p$ values of $>0.05$ failed to establish the level of prior education as a predictor of academic performance in the bio science papers.

Conclusion: The level of prior education was not predictive of the academic performance in the two bio science papers.

Keywords: Academic performance; Admissions/ Selection; Bioscience performance

\section{Introduction}

Bio science papers form the foundational structure of health science programmes and a solid groundwork in the bio sciences is known to enable the appropriate application of scientific evidence. Bio sciences provide a scientific basis for understanding disease and making sound clinical decisions. Though the students recognize the relevance of the bio sciences and believe a good level of knowledge is required, bio sciences continue to remain an impediment for academic progress and a source of apprehension for students [1-3]. Academic performance in bio science subjects has been proven to be a powerful predictor of subsequent academic success $[4,5]$. When the correlation between grade point average for the bio science papers such as introductory anatomy, physiology \& biochemistry and the cumulative graduating grade point average for two hundred and fifty-eight nursing students was calculated, it was found to be statistically significant [6].

The challenges for academic success in the bio science papers may be attributed to a range of issues. Some of these factors include limited prior knowledge of the sciences; language barriers; a limited level of prior education; lack of independent learning skill; lack of efficaciousness for success in bio science; and intensity of workload at university [7]. The level of prior education has been used as predictor of academic performance. Several studies have conclusively demonstrated that students with prior university qualifications are better academic performers with higher grade point averages than school leavers [8,9]. A number of other reasons have also been put forth as explanations including: prior tertiary education experience, clearer motivation, interpersonal skills, developed learning style, confidence, selfdirected learning, and better learning approaches for suboptimal learning [9]. In contrast, there are studies that have found no correlation between the level of prior education and 
academic performance at university $[10,11]$. The purpose of this study was to determine if the level of prior education is predictive of academic performance as measured by the grades obtained in the bio science papers.

\section{Material and Methods}

The research approach is based on the ontological assumption of the nature of reality being objective as the data obtained for this research exists independent of the researchers. The epistemological basis is post-positivism because, in spite of the study data being desensitized and there being a non-relationship between the researchers and the researched, the researchers acknowledge the pluristic nature of the approach owing to the multiple analysis and interpretation possibilities of the data [12]. Though the data is concrete, it has been drawn from mutable situations to predict academic performance in the bio science papers; with an understanding that academic performance is individual, contextual and multifaceted; and there are other variables, some that are known and some that are unknown, that have not been considered in this study. The research method for this retrospective study is the quantitative method. Desensitized data was obtained for this research. It was confirmed by AUTEC (Auckland University of Technology Ethics Committee) that ethics approval was not required for this research. The data was released by the University's data custodian.

The outcome or dependent variables were the grades obtained in the two bio science papers. The predictor or independent variables were age, sex, ethnicity, and level of prior education, the place from where prior education was obtained, and work experience. The sample for this study was a purposive sample of all students who had enrolled in the second-year bio science paper as part of the Bachelor of Health Science (Oral Health) programme at the Auckland University of Technology. The data comprised of the student cohorts over a four-year period from 2011 to 2014. The total sample consisted of 116 students. The grades obtained in the bio science papers in the first and second year were used as outcome variables. Three students had not enrolled in the bio science paper in the first year. The raw de-identified data was entered into IBM SPSS (Statistical Package for Social Sciences) version 22 for windows. The data was subjected to descriptive and inferential statistical tests. Independent sample t tests were applied to compare the grades obtained by those without prior university qualifications to those who had prior university qualifications. The multivariable regression analysis was applied to the final grade in both the bio science papers and the full set of predictor variables to determine the degree to which the predictor variables accounted for the outcome variable. The multiple correlations value (R) was calculated to indicate the strength of the relationship between the predictor variables and the outcome variable. The coefficient of multiple determination $\left(R^{2}\right)$ was calculated to determine the amount of variance in the outcome variable that could be accounted for by the predictor variables. The level of significance for the inferential statistical tests was established at 0.05 .

\section{Result}

Of the 116 students who had completed the second-year bio science paper, fifty-five students had prior university qualifications before enrolling into this course and sixty-one students had declared themselves as school leavers. Of the fifty-five students who had prior university qualifications, forty-nine were female and six were male. The age range of the fifty-five students in their first year of enrolment in this programme ranged between twenty-two and forty-six years. Of the students with prior university qualifications, sixteen students were of European ethnicity, sixteen students were of Asian ethnicity, eleven students had selected 'other' as their ethnicity, six students identified as Maori, five as Pasifika and one student had not declared their ethnicity. Of the fifty-five students nine students did not have work experience but the remaining forty-six reported as having work experience prior to enrolling into the programme. While thirty nine out of the fifty-five had studied in New Zealand, sixteen had obtained prior qualifications overseas. Of the sixty-one school leavers, there were three male students and fifty-eight female students. The age range of the sixty-one students in their first year of enrolment in this programme ranged between eighteen and thirty-eight years.

Table 1: T test for Year I bio science paper and level of prior education $(n=113)$.

\begin{tabular}{|c|c|c|c|c|c|c|c|}
\hline & F & Sig. & t & df & Sig. (2-tailed) & Mean Difference & Std. Error Difference \\
\hline Equal variances assumed & 0.148 & 0.701 & -1.872 & 111 & 0.064 & -3.699 & 1.976 \\
\hline Equal variances not assumed & & & -1.862 & 105.68 & 0.064 & -3.699 & 1.986 \\
\hline
\end{tabular}

Table 2: T test for Year II bio science paper and level of prior education $(n=116)$.

\begin{tabular}{|c|c|c|c|c|c|c|c|}
\hline & F & Sig. & t & df & Sig. (2-tailed) & Mean Difference & Std. Error Difference \\
\hline Equal variances assumed & 0.036 & 0.849 & -0.470 & 114 & 0.640 & -1.183 & 2.519 \\
\hline Equal variances not assumed & & & -0.469 & 111.736 & 0.640 & -1.183 & 2.524 \\
\hline
\end{tabular}

Table 3: Model summary for regression analysis with Year I Bio science paper as outcome variable.

\begin{tabular}{|c|c|c|c|c|}
\hline Model & R & R Square & Adjusted R Square & Std. Error of the Estimate \\
\hline 1 & $0.301^{\mathrm{a}}$ & 0.09 & 0.039 & 10.379 \\
\hline
\end{tabular}


Of the students with prior experience at university, sixteen students were of European ethnicity, fifteen students were of Asian ethnicity, ten students had selected 'other' as their ethnicity, twelve students identified as Maori, and eight as Pasifika. More than half the students had no work experience and fifty-six students had studied previously in a New Zealand school. The means between the grades obtained in the first-year bio science paper by students with prior university qualifications was compared to that obtained by the school leavers (Table 1). The means between the grades obtained in the second-year bio science paper by students with prior academic experience at university was compared to the school leavers (Table 2). A significance of less than 0.05 in both the tests indicates that the means of the scores in the bio science papers of the school leaver group and the group with prior university qualifications are not statistically significantly different. The regression analysis was carried out using the grades obtained in the first year and second year bio science papers as the dependent or outcome variables separately and age, gender, ethnicity, level of prior education, place of prior education, and work experience. Though $9 \%$ of the variation in grades in the first-year bio science paper could be explained to be due to the predictor variables as indicated by the value of $\mathrm{R}$ square (Table 3), none of the predictor variables were statistically significant predictors (Table 4). Similarly, though $6 \%$ of the variation in grades in the second-year bio science paper could be explained to be due to the predictor variables as indicated by the value of $\mathrm{R}$ square (Table 5), none of the predictor variables were statistically significant predictors (Table 6).

Table 4: Regression analysis with Year I Bio science paper as outcome variable.

\begin{tabular}{|c|c|c|c|c|c|}
\hline \multirow{2}{*}{ Model } & \multicolumn{5}{|c|}{ Unstandardized Coefficients } \\
\hline & B & Std. Error & Beta & $\mathbf{t}$ & Sig. \\
\hline (Constant) & 56.251 & 9.951 & & 5.653 & 0 \\
\hline Level of Prior education & 2.575 & 2.307 & 0.122 & 1.116 & 0.267 \\
\hline Age & 0.071 & 0.154 & 0.049 & 0.461 & 0.646 \\
\hline Work Experience & 2.097 & 1.204 & 0.186 & 1.742 & 0.084 \\
\hline Gender & 3.207 & 3.763 & 0.082 & 0.852 & 0.396 \\
\hline Country of prior education & 2.959 & 2.801 & 0.105 & 1.057 & 0.293 \\
\hline Ethnicity & -0.501 & 0.693 & -0.069 & -0.723 & 0.471 \\
\hline
\end{tabular}

Table 5: Model summary of regression analysis with Year II Bio science paper as outcome variable.

\begin{tabular}{|c|c|c|c|c|}
\hline Model & R & R Square & Adjusted R Square & Std. Error of the Estimate \\
\hline 1 & $0.261^{\text {a }}$ & 0.068 & 0.017 & 13.387 \\
\hline
\end{tabular}

Table 6: Regression analysis with Year II Bio science paper as outcome variable.

\begin{tabular}{|c|c|c|c|c|c|}
\hline \multirow[t]{2}{*}{ Model } & \multicolumn{2}{|c|}{ Unstandardized Coefficients } & \multicolumn{3}{|c|}{ Standardized Coefficients } \\
\hline & B & Std. Error & Beta & $\mathbf{t}$ & Sig. \\
\hline (Constant) & 47.518 & 12.767 & & 3.722 & 0 \\
\hline Level of Prior education & -0.856 & 2.943 & -0.032 & -0.291 & 0.772 \\
\hline Age & 0.258 & 0.198 & 0.138 & 1.304 & 0.195 \\
\hline Work Experience & 1.782 & 1.536 & 0.124 & 1.16 & 0.249 \\
\hline Gender & 8.321 & 4.832 & 0.166 & 1.722 & 0.088 \\
\hline Country of prior education & 1.257 & 3.514 & 0.036 & 0.358 & 0.721 \\
\hline Ethnicity & -0.073 & 0.887 & -0.008 & -0.082 & 0.934 \\
\hline
\end{tabular}

\section{Discussion}

Academic performance at university has been a prevalent subject of intense research for many decades for multiple stakeholders including accreditation agencies, governments and the society at large. The academic performance of students with varied background characteristics while at university has stimulated vast research on not only the cognitive measures but also on the non-cognitive attributes. Some of the research findings have been used in formulating the admissions criteria at university.
One such criteria for admission into health science programmes is the level of prior education, with some universities offering admissions to students with prior university qualifications, though there is limited consensus on predictability of prior academic experience at university on subsequent academic performance at university. Though the role of bio sciences in education includes: "development of clinical reasoning", "critical analysis of medical and surgical intervention", and "analysis of processes to improve health care" [13] and performance in bio science subjects has been 
demonstrated to be a particularly powerful predictor of subsequent academic success, [4-6] it has been described as a 'hard' science. Universities across the world are looking at ways to apply admission criteria that could increase the likelihood of student success in the bio sciences, one of which is seeking students with prior academic qualifications at university.

This study has compared the bio science performance of students with and without prior university qualifications in the Bachelor of Health Science (Oral Health) programme in the first year and the second year. Our findings of the level of education not being a significant predictor of academic performance is similar to other studies. In a study on the predictors of academic performance in nursing and paramedicine students, the addition of previous academic qualifications at university did not increase the regression co-efficient with the grade point average in the bio sciences though it did increase the regression co-efficient for the overall grade point average and clinical grade point average [5]. A study on the demographic background and prior academic achievement of individual students entering the University of Newcastle Medical School between 1978 and 1989 did not reveal any correlation between academic outcome and level of prior academic achievement within the top $10 \%$ achievement band studied [10]. So also, a study from New South Wales showed no difference between school leaving entrants and graduate entrants for academic performance, research outcomes or for career positions obtained after qualifying [11]. The authors also found that there were no differences in the levels of the motivation for doing medicine between the two groups.

The findings of our study are however in contrast to the results of other studies that favour students with prior university qualifications over those without prior university qualifications. In a study of medical students, univariate analyses between graduate entrants scores in each of the bio science assessments and the scores obtained by undergraduate students were compared, the graduate entrants had higher average scores [14]. In another study comparing academic performance of graduate entry and school leavers on applied dental knowledge, graduate entry students outperformed the school leavers [15]. When the student characteristics of one hundred and ninety two chiropractic students were analysed, students already possessing a degree had higher grade point averages at the end of their first year of study [8]. Similarly, a large scale study of graduate entry and school leaver medical students revealed that graduate entry students performed as well as school leaver students in phase I examination but a greater number of graduate entry students passed in the final examination, despite being in an accelerated four year programme [9]. In contrast, a Queensland University study of medical students from 1972-1989 found that mature age entrants despite prior tertiary qualifications won less undergraduate honours grades/prizes [16].

In the study sample, the average age of the students with prior university qualifications was higher than that of the cohort without prior university qualifications. Though age has not emerged as a statistically significant predictor for academic performance in our study, the impact of age cannot be undermined. In a study on psychological distress of medical students at the University of Wollongong, anxiety and stress were reported to be higher in the older students [17]. Stress levels as reported by students and salivary cortisol levels has been shown to have an inverse correlation with academic performance [18]. In this study sample, though the distribution of ethnicity was more or less similar in the two groups, a significant number of the students with prior university qualifications had obtained qualifications overseas. Though the place of prior education did not evolve statistically as a predictor in the regression analysis, it could have contributed to the lack of difference when the means of the scores obtained in the bio science papers by the two groups were compared. Migrants and international students are faced with the challenge of adapting to the predominant culture. They are faced with the task of socializing linguistically, socially and academically [19]. Migrant students' unexposed to student-centered learning may find self-directed learning and problem-based learning used in Western Universities challenging [20]. Moreover difficulties of bio science has been attributed to the language [2] and students with limited proficiency in the English language are only likely to have been burdened more.

More than half the students with no prior university qualifications had no work experience in contrast most of the students with prior university qualifications had work experience. Some of these students might have continued to work while studying. Engagement in paid employment during semester terms was found to negatively affect the academic performance of nursing students. In a longitudinal study of nursing students in Australia, there was an inverse relationship between the graduating grade point average and the number of hours in paid employment [21]. This aspect could have resulted in the lack of difference between the academic performances in the bio science papers between the two groups.

\section{Limitations and Future Directions}

This study is based on a small sample from one university within a four-year period and hence the conclusions cannot be generalized. The outcome variables considered were the grades obtained in the two bio science papers, academic success measured by using just the final grades was reductionist and did not take into consideration all aspects of academic achievement. A very limited number of predictor variables have been included for the regression analysis. The two cohorts with and without prior university qualifications have been treated as a homogenous group. Their prior academic achievement or the subjects studied previously have not been taken into consideration. This study has explicitly provided insights for future research. One to which is to replicate the current study using larger samples at other universities in the same discipline. Such studies could help determine if some of the findings are unique to this study. Larger prospective mixed method studies using bigger samples with a greater number of cognitive and non-cognitive predictor variables would shed more light on factors affecting academic performance. However, the findings of this study have implications for education practice in that academic 
experiential characteristics need not be considered a significant entry criteria into courses and universities should continue to offer opportunities to a wider cohort of students.

\section{Conclusion}

The lack of any statistically demonstrable difference in the academic performance of students with and without prior university qualifications highlights the influence of multiple factors on academic performance and this study adds to the findings of other researchers on the level of education as a predictor for academic performance. The conclusions of this study are in line with other studies that have determined that students can achieve similar levels of academic success despite varying levels of prior academic experience [22].

\section{References}

1. Farooq I, Ali S (2014) Comparison of the perceived relevance of oral biology reported by students and interns of a Pakistani dental college. Eur J Dent Educ18(4): 203-206.

2. Craft JA, Hudson PB, Plenderleith MB, Gordon CJ (2017) Enrolled nurses entering undergraduate studies at second year to become registered nurses- A mixed methods study on commencing perceptions of bio science. Collegian 24(4): 317-324.

3. McVicar A, Andrew S, Kemble R (2015) The bio science problem for nursing students: An integrative review of published evaluations of Year 1 bio science, and proposed directions for curriculum development. Nurse Educ Today 35(3):500-509.

4. Peterson CA, Tucker RP (2005) Medical gross anatomy as a predictor of performance on the USMLE Step 1. Anat Rec B New Anat 283(1): 5-8.

5. Whyte DG, Madigan V, Drinkwater EJ (2011) Predictors of academic performance of nursing and paramedic students in first year bio science. Nurse Educ Today 31(8): 849-854.

6. Wong J, Wong S (1999) Contribution of basic sciences to academic success in nursing education. Int J Nurs Stud 36(4): 345-354.

7. Owens A, Moroney T (2017) Shifting the load: Improving bio science performance in undergraduate nurses through student focused learning. Collegian 24(1): 37-43.

8. Green BN, Johnson CD, McCarthy K (2003) Predicting academic success in the first year of chiropractic college. J Manipulative Physiol Ther 26(1): 40-46.
9. Shehmar M, Haldane T, Price Forbes A, Macdougall C, Fraser I, et al. (2010) Comparing the performance of graduate-entry and school-leaver medical students: Comparison of graduate-entry and school-leaver students. Med Educ 44(7): 699-705.

10. Neame RL, Powis DA, Bristow T (1992) Should medical students be selected only from recent school-leavers who have studied science? Med Educ 26(6): 433-440.

11. Rolfe IE, Ringland C, Pearson SA (2004) Graduate entry to medical school? Testing some assumptions. Med Educ 38(7): 778-786.

12. Creswell JW (1994) Research design: Qualitative \& quantitative approaches. Sage Publications, Thousand Oaks, California.

13. Grande JP (2009) Training of physicians for the twenty-first century: Role of the basic sciences. Med Teach 31(9): 802-806.

14. Dodds AE, Reid KJ, Conn JJ, Elliott SL, McColl GJ (2010) Comparing the academic performance of graduate- and undergraduate-entry medical students. Med Educ 44(2): 197-204.

15. Ali K, Zahra D, Tredwin C (2016) Comparison of graduate-entry and direct school leaver student performance on an applied dental knowledge test. Eur J Dent Educ 21(4): 248-251.

16. Harth SC, Biggs JS, Thong YH (1990) Mature-age entrants to medical school: a controlled study of sociodemographic characteristics, career choice and job satisfaction. Med Educ 24(6): 488-498.

17. Casey D, Thomas S, Hocking DR, Kemp Casey A (2016) Graduate-entry medical students: Older and wiser but not less distressed. Australas Psychiatry 24(1): 88-92.

18. Ng V, Koh D, Chia SE (2003) Examination stress, salivary cortisol, and academic performance. Psychol Rep 93(3 Pt 2):1133-1134.

19. Simpson J, Cooke M (2009) Movement and loss: Progression in tertiary education for migrant students. Lang Educ 24(1): 57-73.

20. Frambach JM, Driessen EW, Chan LC, van der Vleuten CP (2012) Rethinking the globalisation of problem-based learning: How culture challenges self-directed learning. Med Educ 46(8): 738-747.

21. Salamonson Y, Everett B, Koch J, Andrew S, Davidson PM (2012) The impact of term-time paid work on academic performance in nursing students: A longitudinal study. Int J Nurs Stud 49(5): 579-585.

22. Feeley AM, Biggerstaff DL (2015) Exam Success at Undergraduate and Graduate-Entry Medical Schools: Is learning style or learning approach more important? A critical review exploring links between academic success, learning styles, and learning approaches among school-leaver entry ("Traditional") and Graduate-Entry ("Nontraditional") Medical Students. Teach Learn Med 27(3): 237-244. 